\title{
Interventional Radiology Procedures for COVID-19 Patients: How we Do it
}

\author{
Chow Wei Too ${ }^{1} \cdot$ David Wei Wen $^{2} \cdot$ Ankur Patel $^{1} \cdot$ Abdul Rahman Abdul Syafiq $^{3} \cdot$ \\ Jian Liu ${ }^{2} \cdot$ Sum Leong ${ }^{1} \cdot$ Apoorva Gogna ${ }^{1} \cdot$ Richard Hoau Gong Lo ${ }^{1}$ • \\ Sonam Tashi ${ }^{1} \cdot$ Kristen Alexa Lee $^{1} \cdot$ Pradesh Kumar $^{1} \cdot$ Sui An Lie $^{4}$. \\ Yoong Chuan Tay ${ }^{5}$ Lai Chee Lee ${ }^{6}$ Moi Lin Ling ${ }^{6}$ Bien Soo Tan ${ }^{1}$. \\ Kiang Hiong Tay ${ }^{1}$
}

Received: 18 March 2020/Accepted: 6 April 2020/Published online: 27 April 2020

(C) Springer Science+Business Media, LLC, part of Springer Nature and the Cardiovascular and Interventional Radiological Society of Europe (CIRSE) 2020

\begin{abstract}
With astonishing speed, COVID-19 has become a global pandemic. As it is uncertain when the pandemic will be controlled, it is crucial for procedurists of all stripes to be familiar and confident in performing procedures for COVID-19 patients to prevent intra-hospital infection. In this article, we will detail our approach on how to perform interventional procedures for COVID-19 patients at the bedside in the isolation room and with the patient transferred to the interventional radiology centre. These
\end{abstract}

Chow Wei Too

toochowwei@gmail.com

1 Department of Vascular and Interventional Radiology, Division of Radiological Sciences Singapore General Hospital, Radiological Sciences Academic Clinical Program, Singhealth-Duke-NUS Academic Medical Centre, Outram Road, Singapore 169608, Singapore

2 Department of Diagnostic Radiology, Division of Radiological Sciences Singapore General Hospital, Radiological Sciences Academic Clinical Program, Singhealth-Duke-NUS Academic Medical Centre, Outram Road, Singapore 169608, Singapore

3 Radiography Department, Division of Radiological Sciences Singapore General Hospital, Radiological Sciences Academic Clinical Program, Singhealth-Duke-NUS Academic Medical Centre, Outram Road, Singapore 169608, Singapore

4 Department of Surgical Intensive Care, Division of Anaesthesiology and Perioperative Medicine, Singapore General Hospital, Outram Road, Singapore 169608, Singapore

5 Department of Pain Medicine, Division of Anaesthesiology and Perioperative Medicine, Singapore General Hospital, Outram Road, Singapore 169608, Singapore

6 Infection Prevention and Epidemiology, Singapore General Hospital, Outram Road, Singapore 169608, Singapore workflows have been developed in conjunction with multiple other stakeholders within our hospital, drawing from valuable lessons we have learnt from the SARS outbreak of 2003.

Keywords COVID-19 • Interventional radiology · Procedures · Policy · Process · Infection control

\section{Introduction}

The coronavirus disease 2019 (COVID-19) outbreak was declared a pandemic by the World Health Organization (WHO) on March 11, 2020 [1]. While COVID-19 is a mild disease in most, an estimated $20 \%$ of afflicted patients can develop a severe form of the illness [2]. The current estimated mortality rate of COVID-19 is $2 \%$, in contrast with rates of $10 \%$ and $34 \%$ in Severe Acute Respiratory Syndrome (SARS) and Middle East Respiratory Syndrome (MERS), respectively [3]. However, it is this milder smouldering infection which has allowed COVID-19 to spread worldwide, riding on the back of globalisation.

In this article, we will focus on the detailed processes when performing interventional radiology (IR) procedures for confirmed and suspected COVID-19 patients. These two groups of patients are handled identically in our institution, should an urgent procedure need to be performed.

Our experience with SARS has prepared us for a disease outbreak like COVID-19 [4, 5]. Local experience from another institution during SARS was reported by Lau et al. 
Table 1 Roles of various other stakeholders

\begin{tabular}{lll}
\hline Stakeholder & Role \\
\hline $\begin{array}{l}\text { 1. Infection prevention and } \\
\text { epidemiology }\end{array}$ & $\begin{array}{l}\text { Formulate infection prevention measures at all points of patient movement. This includes PPE, disinfection } \\
\text { of procedural suites and equipment } \\
\text { Coordinate transfer of patient and to handover/takeover care of patient } \\
\text { 2. Isolation ward staff }\end{array}$ \\
$\begin{array}{l}\text { Manage airway/intubation } \\
\text { Provide intraprocedural monitoring } \\
\text { Coordination of anaesthetic unit personnel before, during and after procedure, including infection control } \\
\text { measures }\end{array}$ \\
$\begin{array}{l}\text { Provide prompt disinfecting services along the patient movement path and procedural areas } \\
\text { Clear predesignated path to the procedure suite to minimise contact with other patients, hospital staff and } \\
\text { visitors }\end{array}$
\end{tabular}

[5]. Twenty-eight IR procedures were performed in 27 patients out of the cohort of 206 SARS patients: 12 pleural effusion drainages, 12 venous access catheter insertions, 1 retrieval of guidewire, 1 IVC filter insertion and 1 biliary drainage and stenting. While the total number of procedures performed by IR for COVID-19 patients may not be many to date, it is still necessary for all IR units to fully prepare themselves for this disease [6].

\section{Methods}

It is a major undertaking for any department to realign the diagnostic and interventional radiology services to combat COVID-19. Our colleagues (Cheng et al.) recently described such processes and included a quick summary checklist of major operational considerations for both diagnostic radiology and IR [7].

\section{Hospital and Radiology Wide Measures}

The early response for our hospital and radiology to COVID-19 has been reported in previous articles [8, 9]. In summary, strict infection prevention measures were implemented and patient throughput reduced with non-urgent procedures postponed to afford the time to plan and get ready for the surge of COVID-19 patients. All interhospital patient transfers will need to be screened for COVID-19. In the event that the transfer is emergent (e.g. stroke thrombectomy from another hospital), the patient will be managed as a suspected COVID-19 patient.

Various strategies of patient and staff segregation, according to the operational needs of each department are enforced to mitigate cross-infection. For example, in our department, inpatient and outpatient procedures are performed in separate locations. Prior to the pandemic, the team of 18 Interventional Radiologists (IRs) covered three different sites on a rotational roster. This has been stopped since the beginning of the outbreak and each site has been assigned its dedicated IRs. Within the largest site at the Singapore General Hospital, the IR department is also divided into two functional IR teams (each team consisting of doctors, nurses and radiographers), and they are discouraged to intermingle socially during and after office hours. If in the instance one of the teams is quarantined, there would still be another to manage urgent cases. Physical distancing for staff within each team is practised during meal times when staff are not wearing their masks, and meal times are staggered.

In our institution, daily updates are sent out by the hospital management in the form of routine instructions with changes highlighted. It is crucial for the IR service to keep up with these changes as they can affect workflow.

\section{Close Collaboration with Other Stakeholders is Crucial}

The processes for infection prevention and transfer of COVID-19 patients should be developed in tandem with other procedural areas in the hospital to achieve synergy and standardisation, for example, the operating theatre and the endoscopy suites. Table 1 shows the various stakeholders and their involvement for the successful execution of these complex workflows, in addition to IR staff. Various scenarios were planned and then rehearsed, after which post-action reviews were conducted to gather feedback. Finalised protocols and pathways were clearly documented and formal endorsement obtained from management before implementation.

\section{Personal Infection Prevention Measures}

COVID-19 is spread via close contact, respiratory droplets, fomites and even possibly the faecal-oral route [10, 11]. In our current practice, all staff in clinical areas don surgical masks. When in direct contact with COVID-19 patients, full personal protection equipment (PPE) is necessary. Full PPE in our IR service includes scrub cap, N95 mask (FFP2 
or FFP3), eye shield, full length gown and gloves. The proper sequence of donning and doffing of PPE can be found on the Centre for Disease Control and Prevention website [12]. There is currently no specific recommendation for use of powered air-purifying respirators (PAPR). While it is an alternative to N95 mask for protection against airborne spread, there are disadvantages such as communication difficulties due to the noise from the blowing air and potential cross-contamination if the filters are not disposed properly or if the hood is not cleaned properly [13]. In our institution, PAPR is used as an alternative for those who failed the mask fit test for N95 mask, and when performing aerosol-generating procedures (AGP) on COVID-19 patients [14]. We consider intubation and per-nasal or per-oral procedures like nasogastric tube insertion to be AGPs. In the scenario where the COVID-19 patient requires intubation for a non-AGP, only the anaesthetic staff will be donning PAPR while the rest of the staff in the procedural room is in full PPE only. It is our institutional practice for staff to shower following procedures involving COVID-19 patients as the final step in self decontamination. Shoes are also to be washed at the shower. All staff are thus encouraged to have a change of garments, including socks.

\section{Location}

All requests for IR procedures on COVID-19 patients will need to be vetted carefully. Non-essential procedures for suspected patients should be performed after they are declared negative for COVID-19 and this will have to be discussed with the referring clinicians. We have demarcated three locations to perform procedures for COVID-19 patients depending on which imaging modality is needed.
Our first choice would be to perform the procedure at the patient's bedside to minimise patient transfer and therefore infection transmission risk. These will largely be ultrasoundguided procedures (US-GP), such as pleural effusion and ascites drainages. Where necessary, portable digital radiography can be used to confirm catheter or wire positions.

If the procedure cannot be performed at the patient's bedside, the next choice would be to perform the procedure at an operating room (OR) designated for COVID-19 patients using a mobile fluoroscopy (C-arm) unit. Ideally, these designated ORs are located remotely from the main OR complex so as not to impede routine hospital workflow as large areas will need to be cordoned off during transfer of these patients [8].

Procedures which require angiography or CT will be performed at our IR Centre (IRC), which will require at least partial shutdown of the entire floor of the department. The recovery area will be turned into a PPE donning and removal area and a path will need to cleared for the patient to enter the procedural suite directly. Hence, this option is reserved only for specialised procedures like stroke thrombectomy or complex procedures requiring our hybrid CT/angiography suite. Within our IRC, two procedure rooms were allocated to manage COVID-19 patients and simulations were conducted to work out detailed processes and workflows. Following the procedure, all areas along the patient's transfer path within IRC will need to be cleaned and disinfected. Detailed workflows for the first and last scenarios will be described. The second scenario closely mirrors that of the third.

Table 2 Personnel involved in bedside procedure

\begin{tabular}{|c|c|c|c|c|}
\hline Initials & Staff & Role & Attire & Remarks \\
\hline \multicolumn{5}{|c|}{ Support team (no patient contact) } \\
\hline $\mathrm{CO}$ & Controller & $\begin{array}{l}\text { Maintains command and control of the entire event and } \\
\text { coordinates with various external parties } \\
\text { Doubles up as runner nurse (RN) }\end{array}$ & $\begin{array}{l}\text { N95/eye } \\
\text { protection }\end{array}$ & $\begin{array}{l}\text { Stays in corridor } \\
\text { Holds walkie-talkie }\end{array}$ \\
\hline \multicolumn{5}{|c|}{ Procedural team } \\
\hline SN & Scrub nurse & Scrubs for procedure & Full PPE & \\
\hline $\mathrm{CN}$ & Circulating nurse & Circulates for procedure & Full PPE & $\begin{array}{l}\text { Moves between rooms. Not to } \\
\text { touch surfaces in ante room } \\
\text { Walkie-talkie in breast pocket }\end{array}$ \\
\hline UR & $\begin{array}{l}\text { Ultrasound } \\
\text { radiographer }\end{array}$ & $\begin{array}{l}\text { Operates US machine and cassette of digital } \\
\text { radiography unit }\end{array}$ & Full PPE & \\
\hline DR & $\begin{array}{l}\text { Digital radiography } \\
\text { radiographer }\end{array}$ & Operates digital radiography unit & Full PPE & Minimal patient contact \\
\hline IR & $\begin{array}{r}\text { Interventional } \\
\text { Radiologist }\end{array}$ & Performs procedure & Full PPE & \\
\hline
\end{tabular}


Table 3 Detailed processes

Bedside procedure in isolation ward

Procedure in IRC

Pre-procedure

IR to confirm indication, urgency and where to perform procedure

$\mathrm{CO}$ to gather team, assign roles and conduct briefing

Gather necessary equipment for a portable procedure

To secure digital radiography unit if needed

Proceed to isolation ward

Wrap imaging equipment

Intra-procedure

$\mathrm{CN}$ to don full PPE, enter isolation room, brief patient, conduct preprocedural checks with $\mathrm{CO}$ via walkie talkie

UR to don full PPE enter room and position US machine

$\mathrm{CN}$ and UR to position patient

SN to enter with full PPE to clean and drape

IR to enter with full PPE to perform procedure

\section{Post-procedure}

Procedure team to remove PPE and equipment as per guidance

Proceed to shower

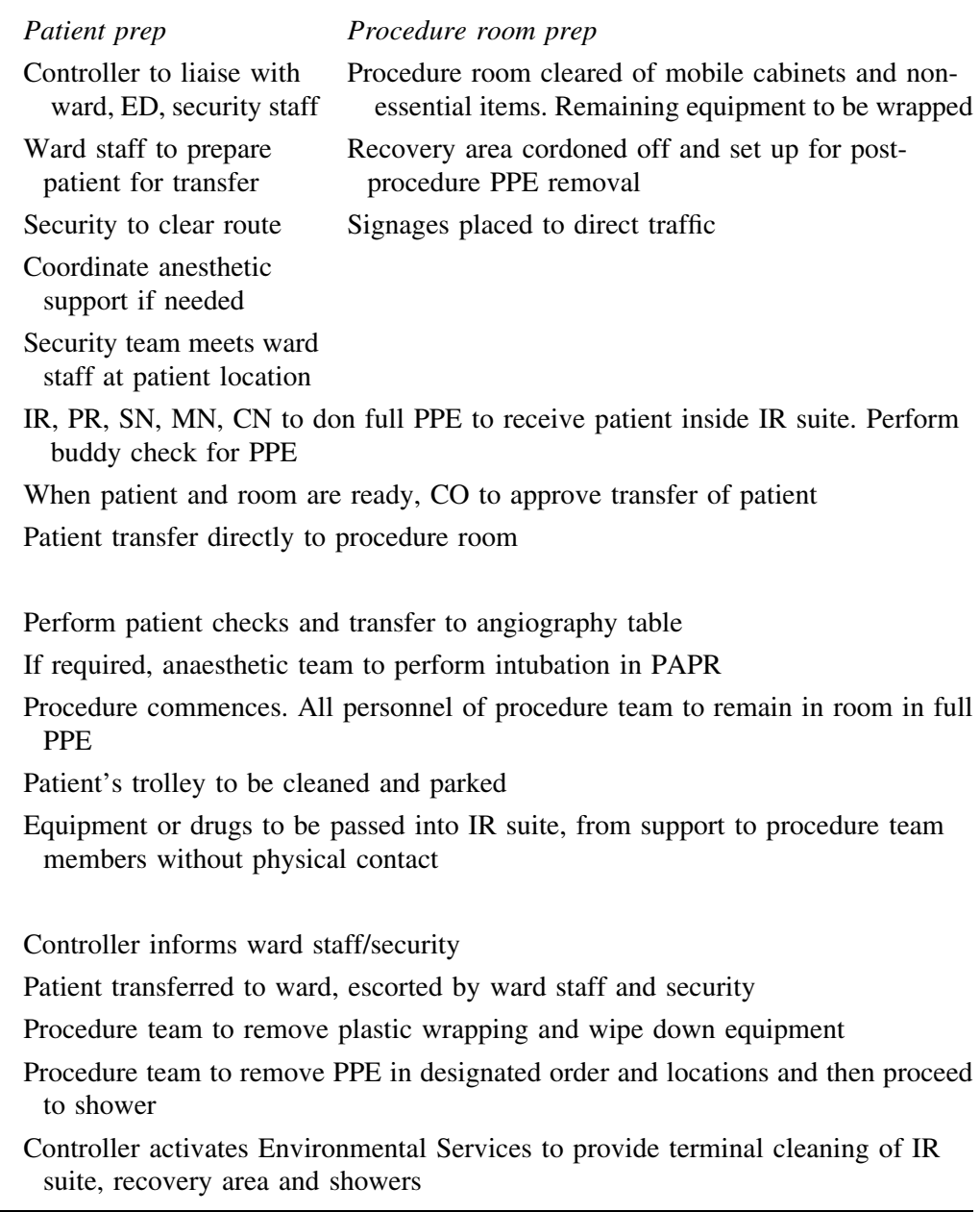

\author{
Controller to liaise with \\ Ward staff to prepare \\ Security to clear route \\ staff at patient location \\ Procedure room prep \\ essential items. Remaining equipment to be wrapped \\ Recovery area cordoned off and set up for post- \\ procedure PPE removal \\ Signages placed to direct traffic \\ buddy check for PPE \\ When patient and room are ready, $\mathrm{CO}$ to approve transfer of patient \\ Patient transfer directly to procedure room
} patient for transfer

Perform patient checks and transfer to angiography table

If required, anaesthetic team to perform intubation in PAPR

Procedure commences. All personnel of procedure team to remain in room in full PPE

Patient's trolley to be cleaned and parked

Equipment or drugs to be passed into IR suite, from support to procedure team

Controller informs ward staff/security

Patient transferred to ward, escorted by ward staff and security

(ape down equipment

Procedure team to remove PPE in designated order and locations and then proceed

Controller activates Environmental Services to provide terminal cleaning of IR

\section{Performing Procedure in the Isolation Room}

In our institution, IR may be required to perform some procedures in the isolation room (central venous catheter insertions, drainages, etc.). The manpower required for such a procedure is listed in Table 2. Table 3 details the steps taken for a portable procedure in the isolation room. Salient points will be highlighted below.

\section{Pre-procedure}

US-GP performed at the bedside will be in the dedicated isolation wards or ICU, with patients in single-bedded rooms. Our dedicated isolation ward rooms are designed such that each one is adjoined with an anteroom. The anterooms are equipped with non-touch hand motion door sensors and interlocking mechanism where both external and internal doors cannot be opened concurrently (Fig. 1). Upon confirmation of the procedure, the controller (CO) and IR will convene the team.

A dedicated ultrasound machine (IU 22, Philips, Amsterdam, the Netherlands) is available in the isolation ward, in anticipation for the need of diagnostic US and US-GPs. The majority of our usual US-GPs involve drainage of symptomatic pleural effusions and ascites, however, in uncommon instances of more complex drainages like percutaneous nephrostomy insertions, arrangements will be made to have the portable digital radiography unit available. The use of digital radiography allows near real-time viewing of radiographs taken at the bedside in order to facilitate immediate confirmation of catheter positions, etc. 


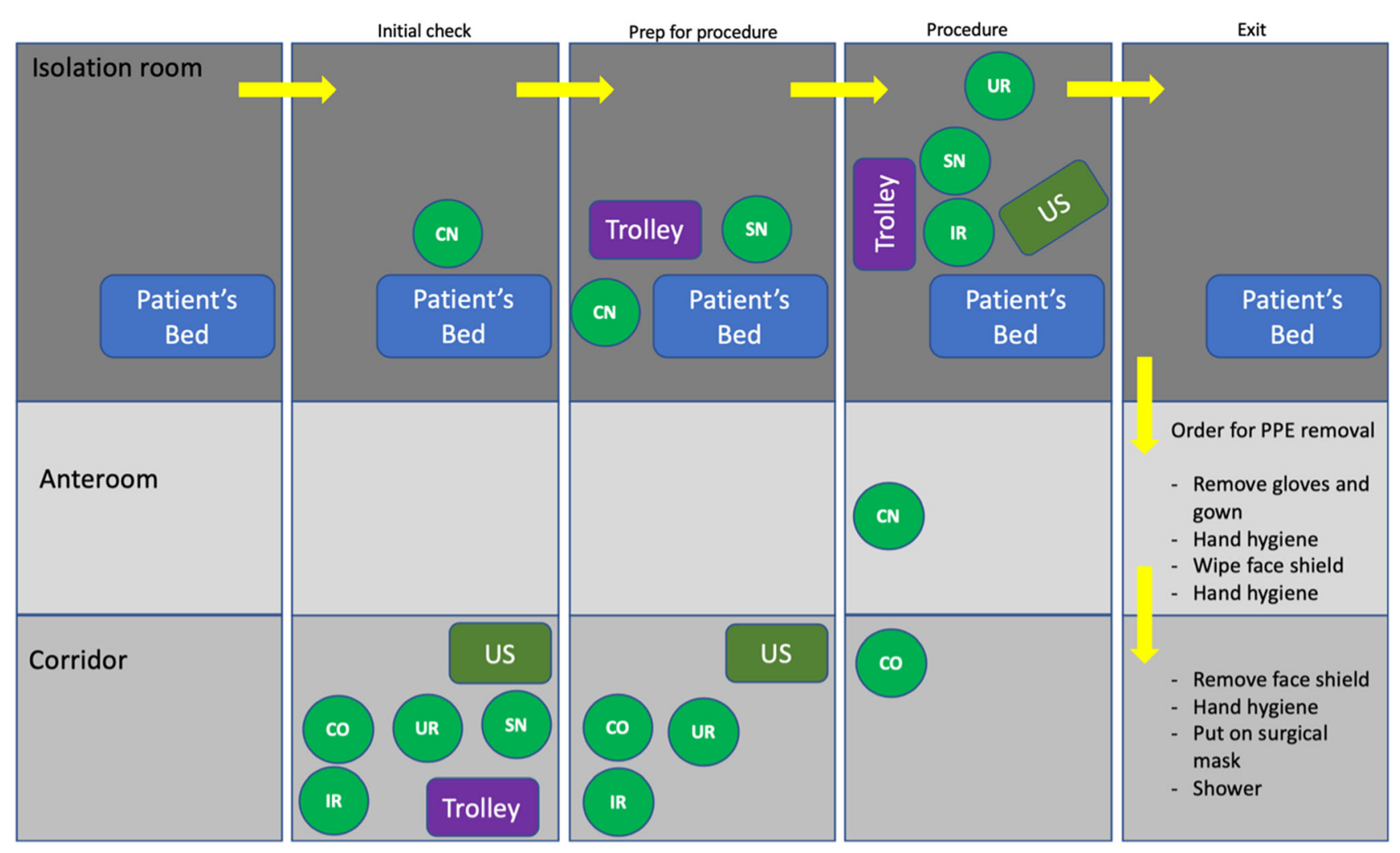

Fig. 1 Schematic diagram of isolation room with staff movement before and during procedure and order for PPE removal

\section{Intra-procedure}

To reduce movement in and out of the room, the IR will forego pre-scanning the patient, deviating from the usual practise. Hence, the circulating nurse $(\mathrm{CN})$ and ultrasound radiographer (UR) will position the patient. A final procedural check can be conducted with the procedural team in the room communicating with the $\mathrm{CO}$ at the corridor via the walkie talkie, as the $\mathrm{CO}$ is checking against patient's notes and consent form. Patient's documents should not be brought into the isolation room. If fluid specimens are required, they will be collected only after the drainage system has been closed and only via a three-way tap. The fluid collected will be distilled gently into the specimen containers directly by the IR to reduce the risk of spillage. Specimens bottles will need to be wiped down and labelled by the $\mathrm{CN}$ in the procedural room before being dropped into the double bag held open by the RN. They will need to be labelled as possible COVID-19 sources, placed in a box and dispatched immediately to the laboratory. Should digital radiography be required, the digital radiographer (DR) will man the machine while the UR will man both the cassette and the US machine.

\section{Post-procedure}

Removal of PPE and disposal of waste should be done meticulously. The order of PPE removal is illustrated in Fig. 1. Clearing of trolley items and plastic wrapping will be performed at the anteroom.

The equipments are to be cleaned with disinfectant wipes (Wip'Anios Excel, Lille-Hellemmes, France). Equipment will then be parked in a designated area for ultraviolet C (UVC) light disinfection. The rest of the procedure team will then proceed to shower and change into a new set of scrubs. Personal particulars of each personnel involved in the procedure are recorded in case contact tracing is needed.

\section{Staff Involved in Procedures at IRC for COVID-19 Patients}

More staff will be needed to perform procedures on COVID-19 patients due to the enhanced infection control measures (Table 4). The key considerations are to maintain command and control of the situation and segregation between the procedural team managing the patient within the procedure suite and the support team who has no direct patient contact. The role of the controller (CO) is crucial; he/she is akin to the conductor of an orchestra, maintaining 
Table 4 Personnel involved in procedure in IRC

\begin{tabular}{|c|c|c|c|c|}
\hline Initials & Staff & Role & Attire & Remarks \\
\hline \multicolumn{5}{|c|}{ Support team (no patient contact) } \\
\hline $\mathrm{CO}$ & Controller & $\begin{array}{l}\text { Maintains command and control of the entire event and coordinates with } \\
\text { various external parties }\end{array}$ & $\begin{array}{l}\text { N95/eye } \\
\text { protection }\end{array}$ & \\
\hline $\mathrm{RN}$ & Runner nurse & Circulates outside room & $\begin{array}{l}\text { N95/eye } \\
\text { protection }\end{array}$ & $\begin{array}{l}\text { Hands equipment over } \\
\text { to } \mathrm{CN} \text { without direct } \\
\text { physical contact } \\
\text { Holds walkie-talkie }\end{array}$ \\
\hline $\mathrm{TN}$ & Traffic nurse & $\begin{array}{l}\text { Manages traffic at entry to department for all personnel involved in } \\
\text { procedure as well as other parties like MRI staff and patients who use } \\
\text { the same corridor }\end{array}$ & $\begin{array}{l}\text { N95/eye } \\
\text { protection }\end{array}$ & \\
\hline $\mathrm{CR}$ & $\begin{array}{l}\text { Control } \\
\text { Radiographer }\end{array}$ & Manages control room & $\begin{array}{l}\text { N95/eye } \\
\text { protection }\end{array}$ & \\
\hline \multicolumn{5}{|c|}{ Procedural team } \\
\hline PR & $\begin{array}{l}\text { Procedure } \\
\quad \text { Radiographer }\end{array}$ & Operates equipment inside procedural room. & Full PPE & \\
\hline $\mathrm{SN}$ & Scrub nurse & Scrubs for procedure & Full PPE & \\
\hline $\mathrm{CN}$ & $\begin{array}{l}\text { Circulating } \\
\text { nurse }\end{array}$ & $\begin{array}{l}\text { Circulates for procedure inside procedure room. room. To minimise } \\
\text { patient contact }\end{array}$ & Full PPE & $\begin{array}{l}\text { Walkie-talkie in the } \\
\text { pocket of the lead suit }\end{array}$ \\
\hline $\mathrm{MN}$ & $\begin{array}{l}\text { Monitoring } \\
\text { nurse }\end{array}$ & Looks after patient in procedure room & Full PPE & \\
\hline IR & $\begin{array}{l}\text { Interventional } \\
\text { radiologist }\end{array}$ & Performs procedure & Full PPE & \\
\hline ANA & $\begin{array}{l}\text { Anaesthetist/ } \\
\text { ICU team }\end{array}$ & Supports patient during procedure. & & \\
\hline
\end{tabular}

situational overview as well as ensuring the whole event is carried out smoothly and safely. The $\mathrm{CO}$ is expected to coordinate multiple personnel across different departments in a crowded and tense environment to provide care for patients who can be critically ill. Allowing only a few nursing leaders to perform the role of $\mathrm{CO}$ will also allow them to be familiar with the workflow and boost confidence.

As there are multiple parties involved, staff are clearly identified by having their roles written on stickers which are stuck to their scrub caps for easy identification. It is paramount that staff working in these designated areas be familiar with their roles and the infection prevention measures required. They also need to keep in mind that more haste is less speed - a slip in infection prevention and control to save a few minutes may result in much longer remedial actions.

Effective communication between the procedure and the control room is maintained either via mounted microphones in the IR suite or hand-held two-way radio transceivers (walkie-talkies) manned by the runner nurse (RN) and the circulating nurse $(\mathrm{CN})$. The $\mathrm{CN}$ put the walkie talkie at the upper pocket of the lead suit and should press the push-to-talk (PTT) button through the gown to maintain. After the procedure, the walkie-talkie will be cleaned in the same manner as the PAPR.

\section{Procedures Requiring Transfer to IRC}

Table 3 details the steps taken for a procedure at IRC with patient transfer. Figure 2 shows the schematic diagram of IRC, manpower deployment and locations for donning and removal of PPE/PAPR.

\section{Pre-procedure}

The transfer of these patients will typically come from the inpatient wards, emergency department or an external hospital (e.g. urgent mechanical thrombectomy for stroke). Upon confirmation of the procedure, the IR will convene a team which includes nurses and radiographers with specified roles, led by the CO. If anaesthetic support is required, they should be notified in advance. All staff involved join a chat group on our hospital's secure text messaging mobile application (TigerConnect, Santa Monica, USA). We have found this effective in coordinating transfers and disseminating information to multiple parties. 


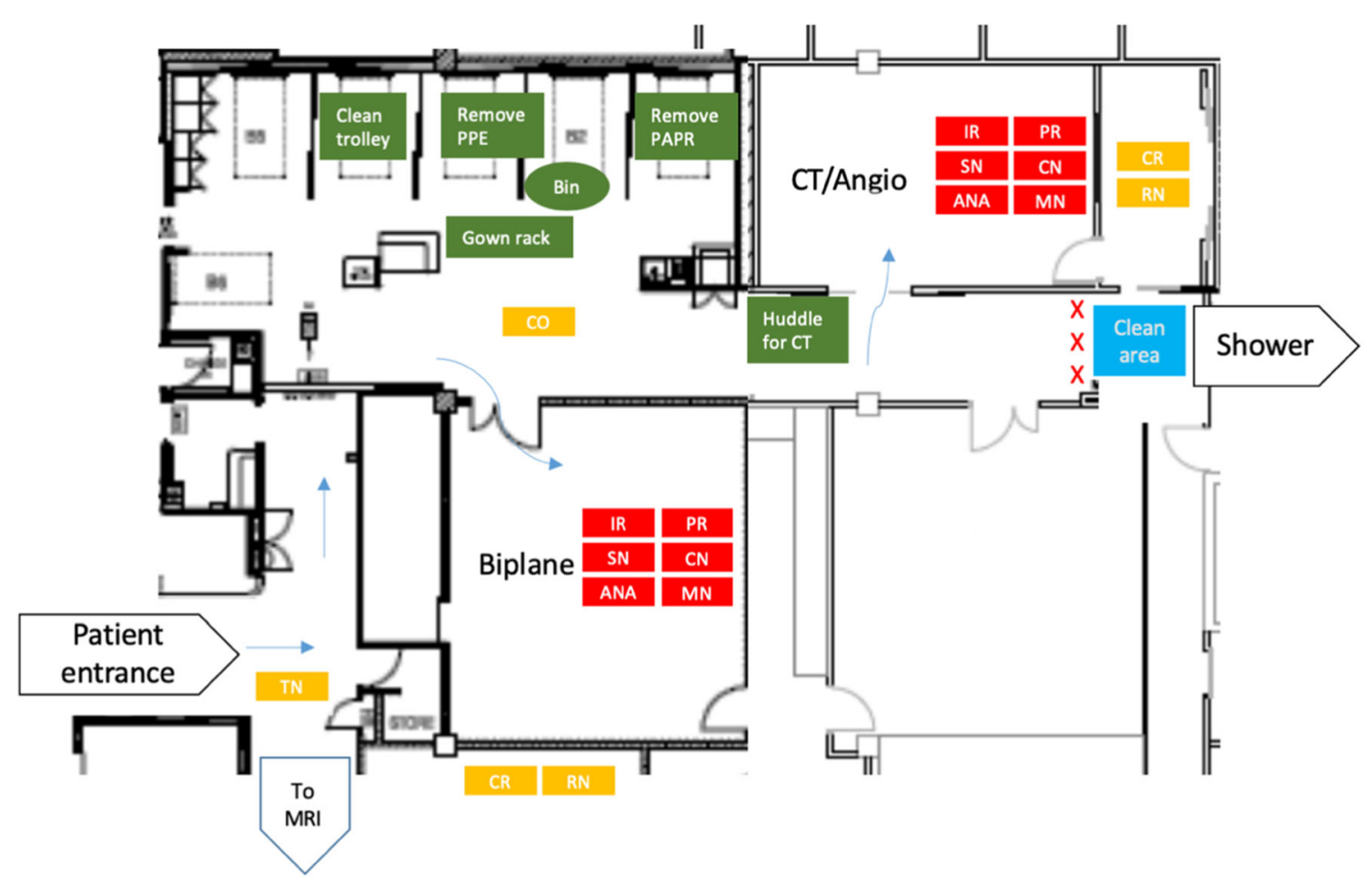

Fig. 2 Schematic drawing of staff locations and patient flow for procedure in IRC

Next, the patient and the IR suite will have to be prepped concurrently as detailed. Patients in the recovery room should be moved out quickly if possible. Procedures in other rooms along the path of transfer which cannot end before the COVID-19 patient is activated should remain in the room till the CO gives the clear signal (after cleaning and disinfection). All items that are non-essential and movable are removed from the suite. Cabinets are either moved out of the suite, have their doors shut and locked or draped with the disposable plastic sheets. The contents of cabinets that are left in the suite during the procedure should not be exposed. A mobile cabinet containing essential equipment (i.e. catheters, guidewires) is positioned just outside the suite for easy access. All other equipment that remains in the suite during the procedure is draped with disposable plastic sheets (Fig. 3A). The traffic nurse (TN) will put up signages along the corridor leading to the IR suite, serving both as a guide for essential personnel and restricting access to others (Fig. 4A-C). Only when all preparation is complete, will the $\mathrm{CO}$ authorise transfer of the patient.

\section{Intra-procedure}

Deviating from routine practise again, the patient will enter the IR suite directly. If required, intubation will be performed at this point by anaesthetic staff who will be in
PAPR (Fig. 3B) while the rest of the staff will be in full PPE without PAPR. For patients who require supplemental oxygen for a conscious sedation/local anaesthesia procedure, oxygen via nasal cannula can be given under a surgical mask. After the commencement of the procedure, all personnel in the room are not to leave the room unless absolutely necessary. Equipment or medications that are required during the course of the procedure are handed from the runner nurse $(\mathrm{RN})$ outside the IR suite to the circulating nurse $(\mathrm{CN})$ via the control room door. Care is taken to avoid contact between the procedure and support team members. All consumables passed into the IR suite but not used is assumed to be contaminated and thus disposed.

\section{Post-procedure}

Once the procedure is finished, the $\mathrm{CO}$ is notified and preparations made to transfer the patient to the ward. The team will continue to be vigilant about infection prevention as there is a high likelihood of contamination during removal of PPE. Gloves and gowns are removed in the IR suite, the face shield wiped and hand hygiene performed. The team then proceeds to the recovery area to remove their protective lead gown, N95 mask and eye shield. The anaesthetic staff will similarly remove and clean their 

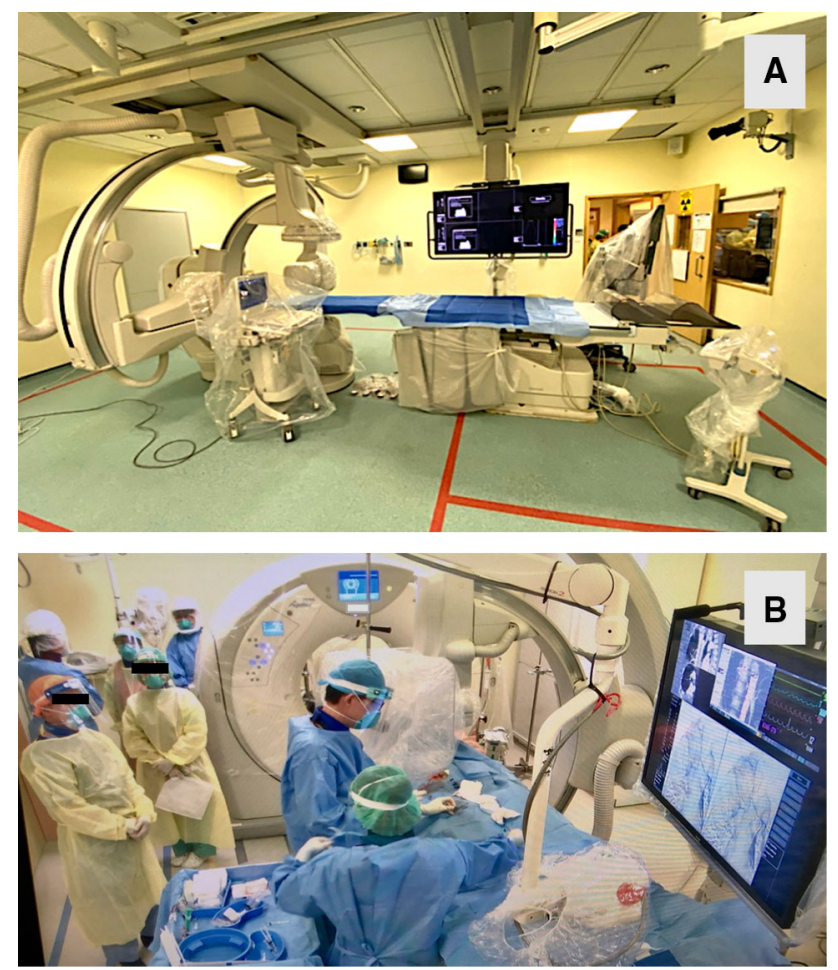

Fig. 3 Designated rooms for COVID-19 patients. A Biplane suite with mobile cabinets removed and equipment wrapped. B Hybrid CT/ Angiography suite during bronchial artery embolisation for a suspected COVID-19 patient. Located at the far left upper corner of the image are ICU staff in PAPR as they need to manage the airway. The rest of the staff are in full PPE without PAPR

PAPR in the recovery area. (Figure 4D). Hand hygiene is performed and a new set of surgical masks donned. The entire procedure team will then proceed to shower and change into a new set of scrubs. When all staff have left the IR suite and shower area, the $\mathrm{CO}$ will activate the hospital environmental services to provide cleaning of the IR suite, temporary recovery area, corridors along the patient transfer path and the showers.

\section{Miscellaneous}

\section{Biological Waste}

If the patient needs to relieve himself or herself before the procedure, biological waste will be doubled bagged and disposed off into the biohazard bag in the room.

\section{CT Scan During Procedure}

If intraprocedural CT scan is required, all staff should exit the procedure suite via the main door and stand in a designated area, making sure not to touch the walls or to come into contact with other personnel. If available, doors should be put to the automatic motion detection mode to allow staff to enter/exit the room without the need to touch the door surface. Once the CT is performed, staff can return to the procedure suite and the external area where they stood will be disinfected.

\section{Disinfecting the Procedure Room}

First, all imaging equipment inside the room are to be wiped down with disinfectant wipes (Wip'Anios Excel, Lille-Hellemmes, France). The floor and the walls of the procedure suite, recovery area and corridors will then undergo terminal cleaning with sodium hypochlorite solution $1000 \mathrm{ppm}$. Additionally, per our institutional protocol, ultraviolet C (UVC) light disinfection will be carried out by dedicated teams from environmental services [15]. The room will need to be aired for 20-30 min. Hydrogen peroxide vapour may be a more effective disinfection agent [16] but there is the risk of aerosol exposure, and thus a wait time of 4-6 $\mathrm{h}$ is needed for the hydrogen peroxide to be removed from the environment before safe use. Waste from the room will be disposed by a dedicated team.

\section{Results}

At the time of publication, all our cases were suspected COVID-19 patients. We have performed two bedside pleural drainage procedures for the same patient in the isolation ward. At the IRC, we have performed two stroke thrombectomies and one bronchial artery embolisation (the patient also needed an on table CT scan prior to the procedure).

\section{Discussion}

As the Chinese saying goes, train an army for a 1000 days to use for one morning. These detailed and laborious processes were collectively worked out by all stakeholders to keep our patients and staff safe. During the formulation of such processes, staff should concurrently undergo infection prevention refresher training, N95 mask fitting and PAPR training if required.

Everyone must bear in mind that the greatest risk of contamination may occur after the procedure is over. Meticulous PPE doffing technique, a buddy system to catch errors and designated spacious areas equipped with visual reminders and sufficient cleaning equipment are vital.

It is highly recommended that simulations and afteraction reviews be performed. The roles of the $\mathrm{CO}$ and the $\mathrm{TN}$ were created after we found that additional personnel were required to manage the whole team. The decision to 

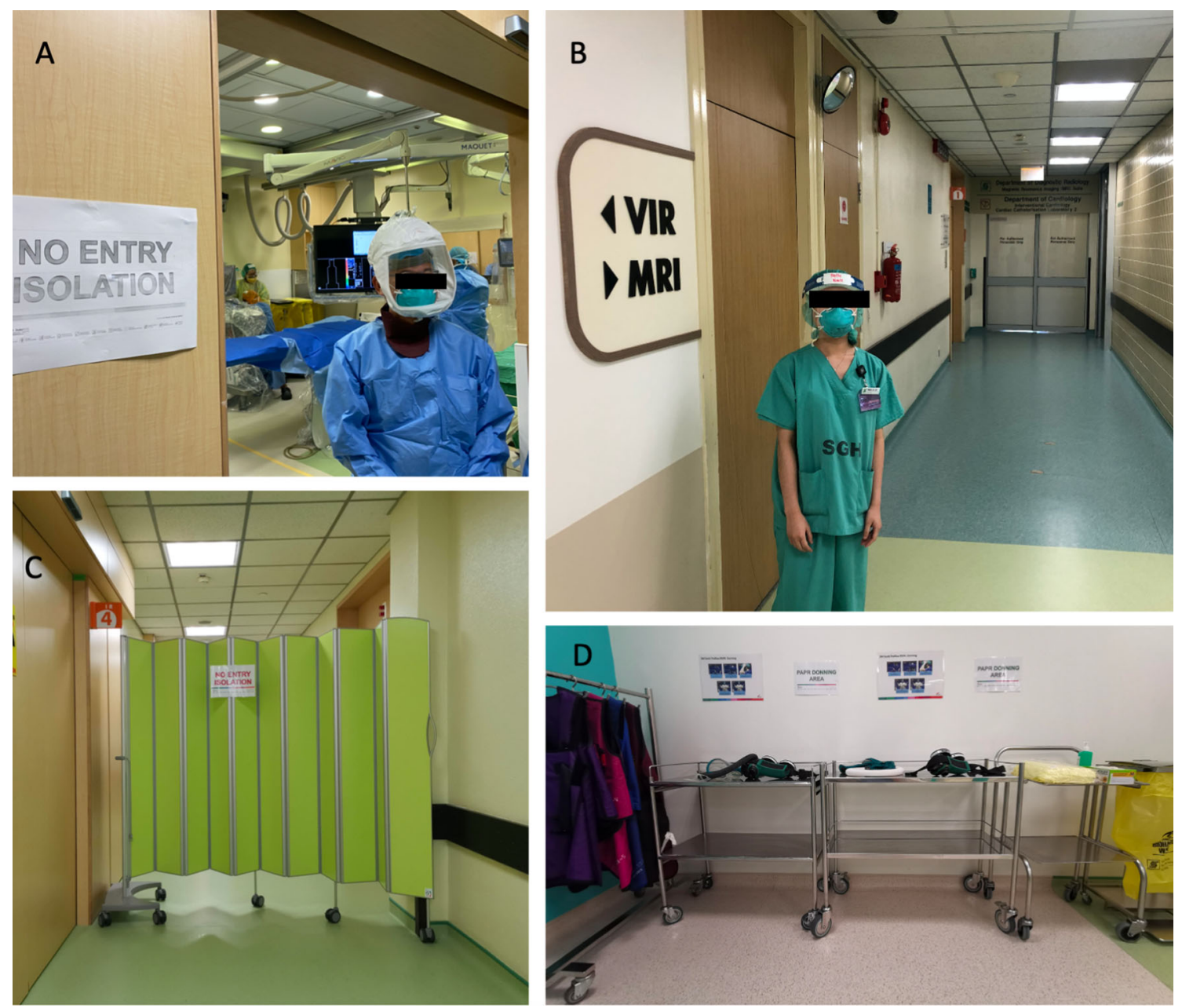

Fig. 4 Various measures to ensure infection prevention. A Clear signage to prevent wrong entry, staff in PAPR. B Traffic nurse identified by label at scrub cap, situated at entrance. C Clear

demarcation of clean and dirty areas. D PPE donning and removal stations with posters with step by step instructions

expose more staff to the process was not taken lightly. We reasoned that as the $\mathrm{CO}$ and the $\mathrm{TN}$ did not have direct patient contact, the benefits of having them contribute to a more controlled and calm process outweighed the small risk of exposure. The walkie talkie was introduced as we found that the nurses are generally not situated near the mounted microphones and had problems communicating. All steps in the process were documented after they were finalised, with charts and schematic diagrams distributed to the rest of the team.

While we expect fewer pleural drainages for COVID 19 patients as pleural effusion seems to be a rare occurrence in this disease [17], given the protracted manner of the pandemic and the large number of infected patients, there may be COVID-19 patients afflicted with other conditions which require urgent IR procedures. The need for developing robust processes is thus urgent, even if the possibility of performing a procedure on a COVID-19 patient seemed remote at the early part of the pandemic.

We recognise that these processes were developed in our local environment which may be different from that available in other centres. Each centre will have to come up with their own processes based on the principles we have shared. The CDC has a useful resource for interim infection prevention and control measures [18].

\section{Conclusion}

The COVID-19 pandemic situation is fluid and the operational processes will need to evolve to adapt to rapid changes. We hope that by sharing these detailed processes, each IR service can develop their own strategies to manage COVID19 patients. Difficult transitions will need to be made, particularly with patient load reduction and staff segregation. It 
can be challenging to close off an entire section of the department just to perform one procedure for a COVID-19 patient. However, this is a small price to pay to ensure the safety of our staff and our patients. The early phase of an outbreak is when decisive and effective actions can dramatically reduce spread. Lessons learnt from this pandemic can be applied to other emerging infectious diseases. IR suites of the future should also take into account pandemic situations during their conception and design.

Funding This study was not supported by any funding.

\section{Compliance with Ethical Standards}

Conflict of interest The authors declare that they have no conflict of interest.

Consent for Publication For this type of study consent for publication is not required.

Ethical Approval This article does not contain any studies with human participants performed by any of the authors.

Informed Consent For this type of study informed consent is not required.

\section{References}

1. WHO Director-General's opening remarks at the media briefing on COVID-19-11 March 2020. Available from: https://www.who. $\mathrm{int} / \mathrm{dg} / \mathrm{speeches/detail/who-director-general-s-opening-remarks-}$ at-the-media-briefing-on-covid-19-11-march-2020.

2. Wu Z, McGoogan JM. Characteristics of and important lessons from the coronavirus disease 2019 (COVID-19) outbreak in China: summary of a report of 72314 cases from the Chinese Center for Disease Control and Prevention. JAMA. 2020. https:// doi.org/10.1001/jama.2020.2648.

3. Mahase E. Coronavirus covid-19 has killed more people than SARS and MERS combined, despite lower case fatality rate. BMJ. 2020;368(PG-m641):m641.

4. Gogna A, Tay KH, Tan BS. Severe acute respiratory syndrome: 11 Years later-a radiology perspective. Vol. 203, American Journal of Roentgenology. American Roentgen Ray Society; 2014. p. 746-8.

5. Lau TN, Teo N, Tay KH, Chan LL, Wong D, Lim WEH, et al. Is your interventional radiology service ready for SARS? The Singapore experience. Vol. 26, CardioVascular and Interventional Radiology. Springer, New York;2003, pp. 421-7.
6. Pua $\mathrm{U}$, Wong D. What is needed to make interventional radiology ready for COVID-19? Lessons from SARS-CoV epidemic. Korean J Radiol. 2020. https://doi.org/10.3348/kjr.2020.0163.

7. Cheng LT, Chan LP, Tan BH, et al. Déjà Vu or Jamais Vu? How the severe acute respiratory syndrome experience influenced a Singapore Radiology Department's Response to the coronavirus disease (COVID-19) epidemic. Am J Roentgenol. 2020. https:// doi.org/10.2214/AJR.20.22927.

8. Wong J, Goh QY, Tan Z, et al. Preparing for a COVID-19 pandemic: a review of operating room outbreak response measures in a large tertiary hospital in Singapore [Se préparer pour la pandémie de COVID-19: revue des moyens déployés dans un bloc opératoire d'un grand hôpital tertiaire au Singapour]. Can J Anaesth. 2020. https://doi.org/10.1007/s12630-020-01620-9.

9. Da Zhuang K, Tan BS, Tan BH, Too CW, Tay KH. Old threat, new enemy: is your interventional radiology service ready for the coronavirus disease 2019? Cardiovasc Intervent Radiol. 2020. https://doi.org/10.1007/s00270-020-02440-6.

10. Transmission of coronavirus disease 2019 (COVID-19) CDC. Available from: https://www.cdc.gov/coronavirus/2019-ncov/ prepare/transmission.html.

11. Gu J, Han B, Wang J. COVID-19: gastrointestinal manifestations and potential fecal-oral transmission. Gastroenterology. 2020. https://doi.org/10.1053/j.gastro.2020.02.054.

12. Protecting Healthcare Personnel HAI CDC. Available from: https://www.cdc.gov/hai/prevent/ppe.html.

13. Roberts V. To PAPR or not to PAPR? Vol. 50, Canadian Journal of Respiratory Therapy. Canadian Society of Respiratory Therapists; 2014, pp. 87-90.

14. Tran K, Cimon K, Severn M, Pessoa-Silva CL, Conly J. Aerosol generating procedures and risk of transmission of acute respiratory infections to healthcare workers: a systematic review. Vol. 7, PLoS ONE. Public Library of Science;2012.

15. Welch D, Buonanno M, Grilj V, et al. Far-UVC light: a new tool to control the spread of airborne-mediated microbial diseases. Sci Rep. 2018;8(1):2752. https://doi.org/10.1038/s41598-018-21058w.

16. Havill NL, Moore BA, Boyce JM. Comparison of the microbiological efficacy of hydrogen peroxide vapor and ultraviolet light processes for room decontamination. Infect Control Hosp Epidemiol. 2012;33(5):507-12.

17. Bernheim A, Mei X, Huang M, et al. Chest CT findings in coronavirus disease-19 (COVID-19): relationship to duration of infection. Radiology. 2020. https://doi.org/10.1148/radiol. 2020200463.

18. Interim infection prevention and control recommendations for patients with suspected or confirmed coronavirus disease 2019 (COVID-19) in healthcare settings. Available from: https://www. cdc.gov/coronavirus/2019-ncov/infection-control/controlrecommendations.html.

Publisher's Note Springer Nature remains neutral with regard to jurisdictional claims in published maps and institutional affiliations. 